\title{
PSYCHE.
}

\section{THE HABITS AND NOTES OF THE NEW ENGLAND SPECIES OF OECANTHUS.}

BY WALTER FAXON, CAMBRIDGE, MASS.

(In a Letter to S. H. Scudder.)

Two years ago I became a good deal interested in our Oecanthi. I found four species in the region about Cambridge, all of them distinct in their markings, and all save one readily distinguished by their habits and notes.

r. Oec. niveus; whitish-green, with a roundish black spot on basal segment of antennae, and another on the second segment. The song is the well-known rhythmical cricket-note of autumn evenings.

2. Oec. angustipennis; greenish-white, more niveous than niveus! Like the last, chiefly nocturnal, singing on trees and shrubs. Basal joints of the antennae with crescentic black marks. Song entirely different from that of niveus, consisting of a trill of several seconds' duration, succeeded by a short pause; this song suggests the spring note of the toad, heard afar off.

3. Oec. nigricornis; strong yellowish cast on the wings; legs and antennae with a good deal of fuscous; basal segments of antennae marked thus [showing a figure with a heavy digamma on the basal joint and two longitudinal lines on the second joint], though the pattern is often obscured by the fuscous suffusion of the whole antennae. Note a long continuous $r-r-r-r-r$, which sounds in a small way like a Cicada. Diurnal, singing particularly on low herbs, Solidago etc., on edges of swamps and also in dry fields.

4. Oec. 4-punctatus; similar to Oec. nigricornis, but antennal joints marked thus [the second joint as in the last; the basal with a reversed figure 7 , the short arm followed by a dot]. Rarest of the four species about here; diurnal, found on herbs in dry fields. Song similar to that of No. 3 , but clearer in tone and no doubt sufficiently distinct on close acquaintance. I have found only two or three of this species, in Cambridge and Lexington.

I have found all four of these species within a few rods of the Museum. 

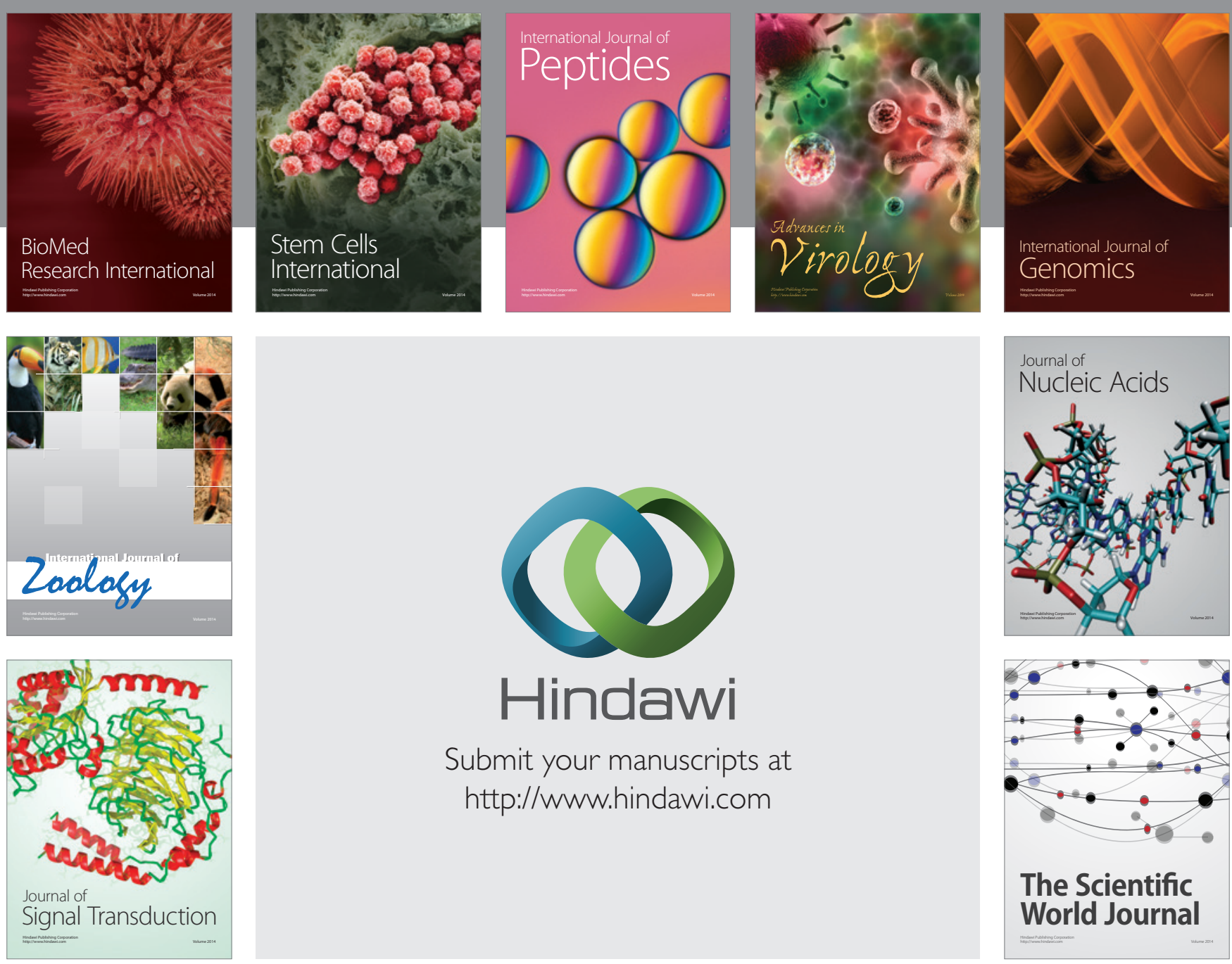

Submit your manuscripts at

http://www.hindawi.com
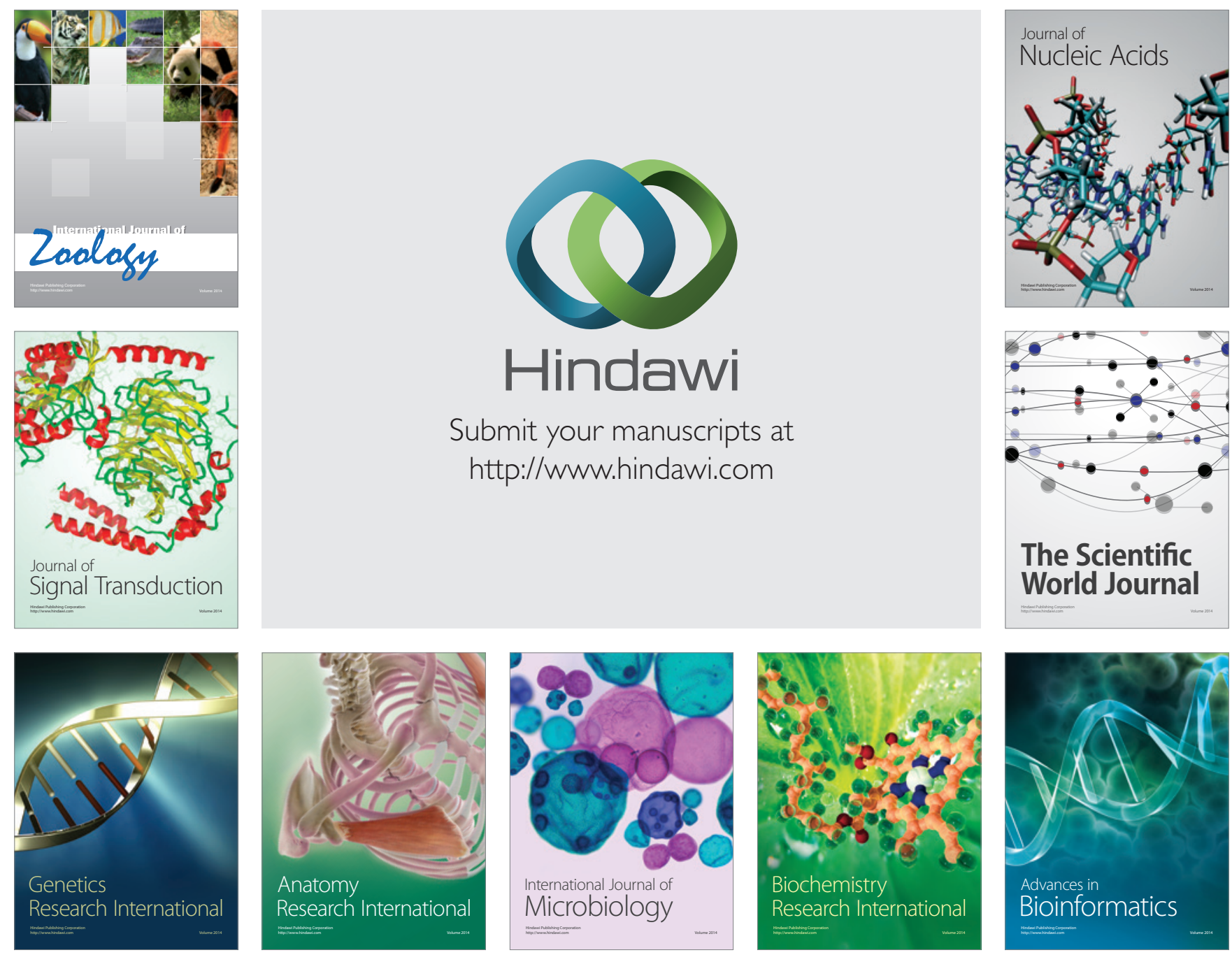

The Scientific World Journal
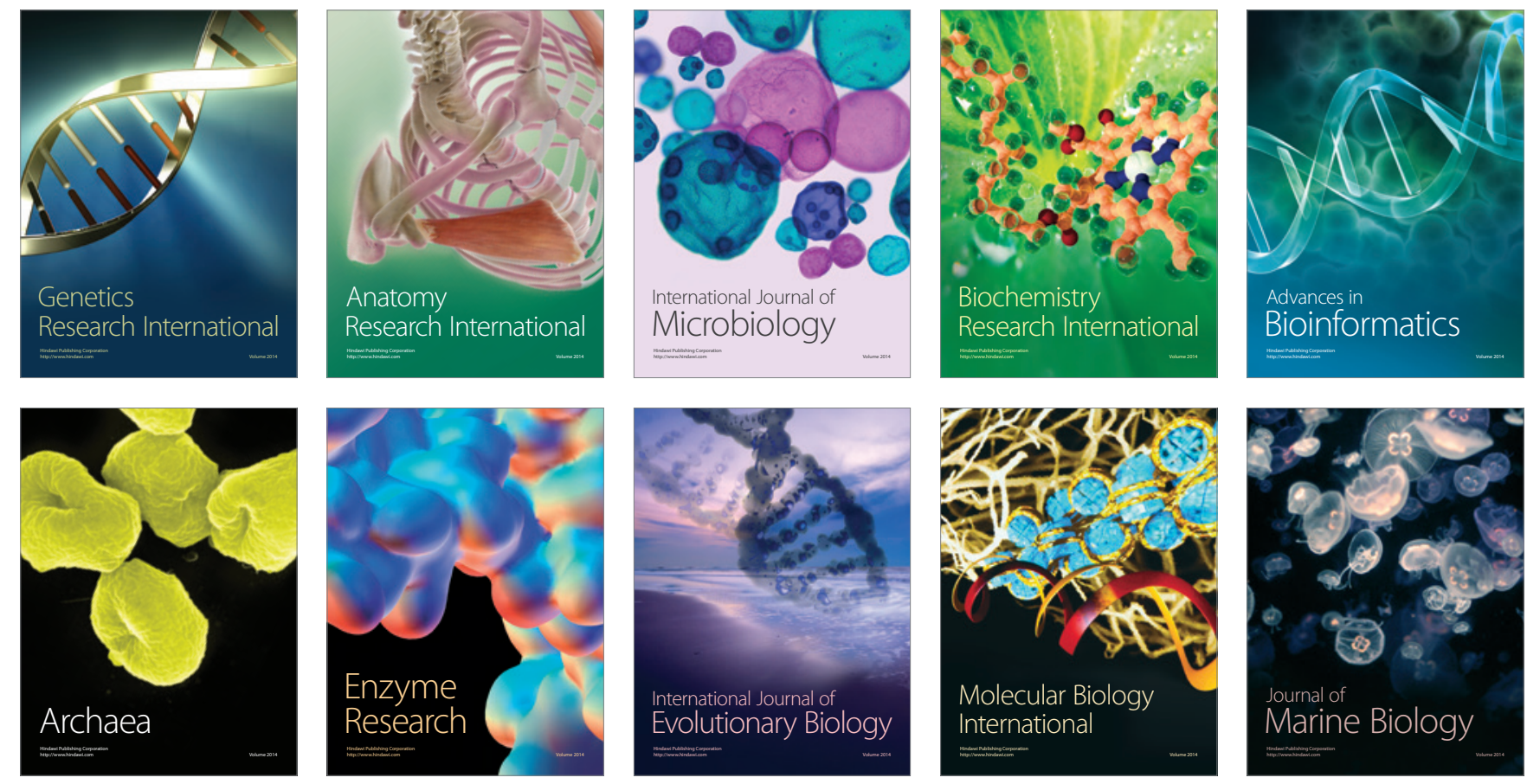